PROFESSOR KETAN DHATARIYA (Orcid ID : 0000-0003-3619-9579)

Article type : Clinical Conundrums

Title: Diabetic Medicine

Created by: Maria Davie

Email proofs to: ketan.dhatariya@nnuh.nhs.uk

Article no.: DME-2020-00184

Accepted date: 8 April, 2020

Article type: Clinical Conundrums

Figures:4; Tables:0; Equations:0; References: 3

Short title: Lipaemia retinalis

Author running head: S. Gaur et al.

\title{
Pale retinal vessels in newly diagnosed type 2 diabetes
}

S. Gaur ${ }^{1}$, D. Bawden ${ }^{1}$ and K. K. Dhatariya ${ }^{1,2}$

${ }^{1}$ Elsie Bertram Diabetes Centre, Norfolk and Norwich University Hospitals NHS Foundation Trust and ${ }^{2}$ Norwich Medical School, University of East Anglia, Norwich, UK

Correspondence to: Prof Ketan Dhatariya. E-mail: ketan.dhatariya@nnuh.nhs.uk

\section{Introduction}

A previously well 52-year-old man was seen with a 3-week history of hyperglycaemic symptoms. He had a BMI of $40.8 \mathrm{~kg} / \mathrm{m}^{2}$, with no evidence of eruptive xanthomas. His random blood glucose

This article has been accepted for publication and undergone full peer review but has not been through the copyediting, typesetting, pagination and proofreading process, which may lead to differences between this version and the Version of Record. Please cite this article as doi: 10.1111/DME.14305

This article is protected by copyright. All rights reserved 
was $19.0 \mathrm{mmol} / \mathrm{l}$ (reference range 3.5-6.9 mmol/1), with an $\mathrm{HbA}_{1 \mathrm{c}}$ concentration of 128 (28-42) $\mathrm{mmol} / \mathrm{mol}$ [13.9 (4.7-6.0)\%]. A venous blood sample was reported as being 'turbid', with a serum triglyceride level of $128.4(0.5-1.7) \mathrm{mmol} / \mathrm{l}$. His visual acuity was normal. He was started on twice-daily biphasic insulin and atorvastatin. One month later, his triglycerides were $7.97 \mathrm{mmol} / 1$, with a total cholesterol level of $5.9(3.6-5.0) \mathrm{mmol} / \mathrm{l}$ and an HDL cholesterol level of $0.72(>1.00)$ $\mathrm{mmol} / \mathrm{l}$. Three months after presentation, his $\mathrm{HbA}_{1 \mathrm{c}}$ level was $41 \mathrm{mmol} / \mathrm{mol}$. His retinal imaging is shown at presentation (Figs 1 and 2) and 12 months later (Figs 3 and 4).

\section{Questions}

1. What is the most likely explanation for his retinal findings?

2. What are the differential causes of hypertriglyceridaemia?

3. What is the most frequently described pattern of dyslipidaemia in poorly controlled diabetes, and why is this case?

\section{Discussion (answers)}

\section{Question 1}

The retinal images of the man's right eye at presentation [temporal/macular image (Fig. 1) and nasal image (Fig. 2)] show lipaemia retinalis. This is a condition characterized by a creamy appearance of the retinal blood vessels attributable to the hyperlipidaemia. This finding is typically only present when the circulating triglyceride concentrations are $>45 \mathrm{mmol} / \mathrm{l}$. It is usually asymptomatic, but there are case reports of reduced visual acuity.

Figure 3 (temporal/macular) and Fig. 4 (nasal) show the retinal vessels of the man's right eye after normalization of the dyslipidaemia with glycaemic optimization and statin use.

\section{Question 2}

The causes of hypertriglyceridaemia can be divided into primary and secondary categories [1]. Primary causes are rare, and include a collection of genetic conditions affecting triglyceride metabolism, such as familial dysbetalipoproteinaemia, familial combined hyperlipidaemia, lipoprotein lipase deficiency, apolipoprotein CII deficiency, apolipoprotein CII deficiency, 
apolipoprotein C-III overproduction, ANGPLT3 overproduction and cholesterol ester storage disease.

Secondary causes are more common and include poorly controlled diabetes mellitus, obesity, excessive alcohol consumption, hypothyroidism, pregnancy, obesity, nephrotic syndrome, renal failure, myeloma, systemic lupus erythromatosis and drugs including glucocorticoids, tamoxifen, oestrogen and $\beta$-blockers. It may be associated with pancreatitis [2]

\section{Question 3}

Insulin is required to stimulate the synthesis of lipoprotein lipase inside adipocytes. This enzyme translocates to the endothelium and enhances clearance of lipids (e.g. chylomicrons and very-lowdensity lipoproteins). If insulin action is impaired or concentrations low, then lipoprotein lipase gene expression is not stimulated, leading to low clearance of these lipid particles. This leads to low concentrations of lipid particles with higher protein content, leading to the classic dyslipidaemia of poorly controlled diabetes: high concentrations of triglycerides, very-low-density lipoproteins and low-density lipoprotein, and low concentrations of high density lipoprotein [3].

\section{Learning points}

1. Lipaemia retinalis is a rare ocular manifestation of hypertriglyceridaemia. Although not a sightthreatening condition, it should be considered in people with secondary hyperlipidaemia.

2. Hyperlipidaemia associated with lipaemia retinalis may predispose individuals to other vascular pathologies, including cerebrovascular and cardiovascular events, as well as pancreatitis, and should prompt early treatment.

3. Lifestyle modification, intensive insulin therapy and the use of lipid-lowering therapies may normalize the lipoid concentrations and thus the retinal vessel abnormalities. Visual acuity in symptomatic patients also improves.

\section{Funding sources}

None.

\section{Competing interests}


None declared.

\section{References}

[1] Rymarz E, Matysik-Wozniak A, Baltaziak L, Prystupa A, Sak J, Grzybowski A. Lipemia retinalis - an unusual cause of visual acuity deterioration. Med Sci Monit 2012; 18:CS72CS75.

[2] Horton M, Thompson K. Lipemia retinalis preceding acute pancreatitis. J Am Optom Assoc $2011 ; 82: 475-480$.

[3] Goldberg IJ. Diabetic dyslipidemia: Causes and consequences. J Clin Endocrinol Metab 2001; 86:965-971.

FIGURE 1 Temporal/macular image of right eye at the time of presentation, showing pale retinal vessels.

FIGURE 2 Nasal image of right eye at the time of presentation, showing pale retinal vessels.

FIGURE 3 Temporal/macular image of right eye, 1 year after presentation, with glycaemic and lipid optimization.

FIGURE 4 Nasal image of right eye, 1 year after presentation, with glycaemic and lipid optimization. 


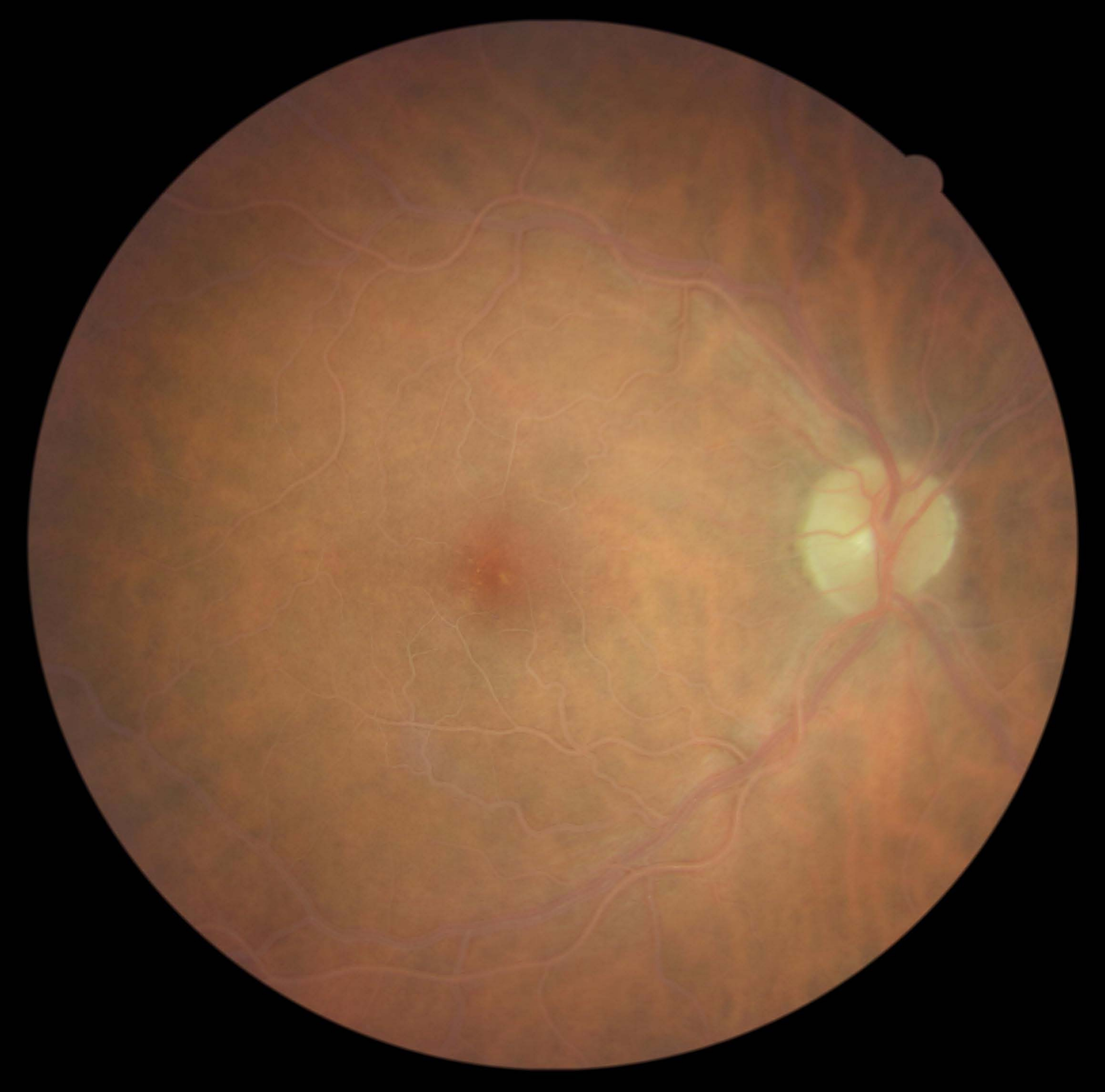




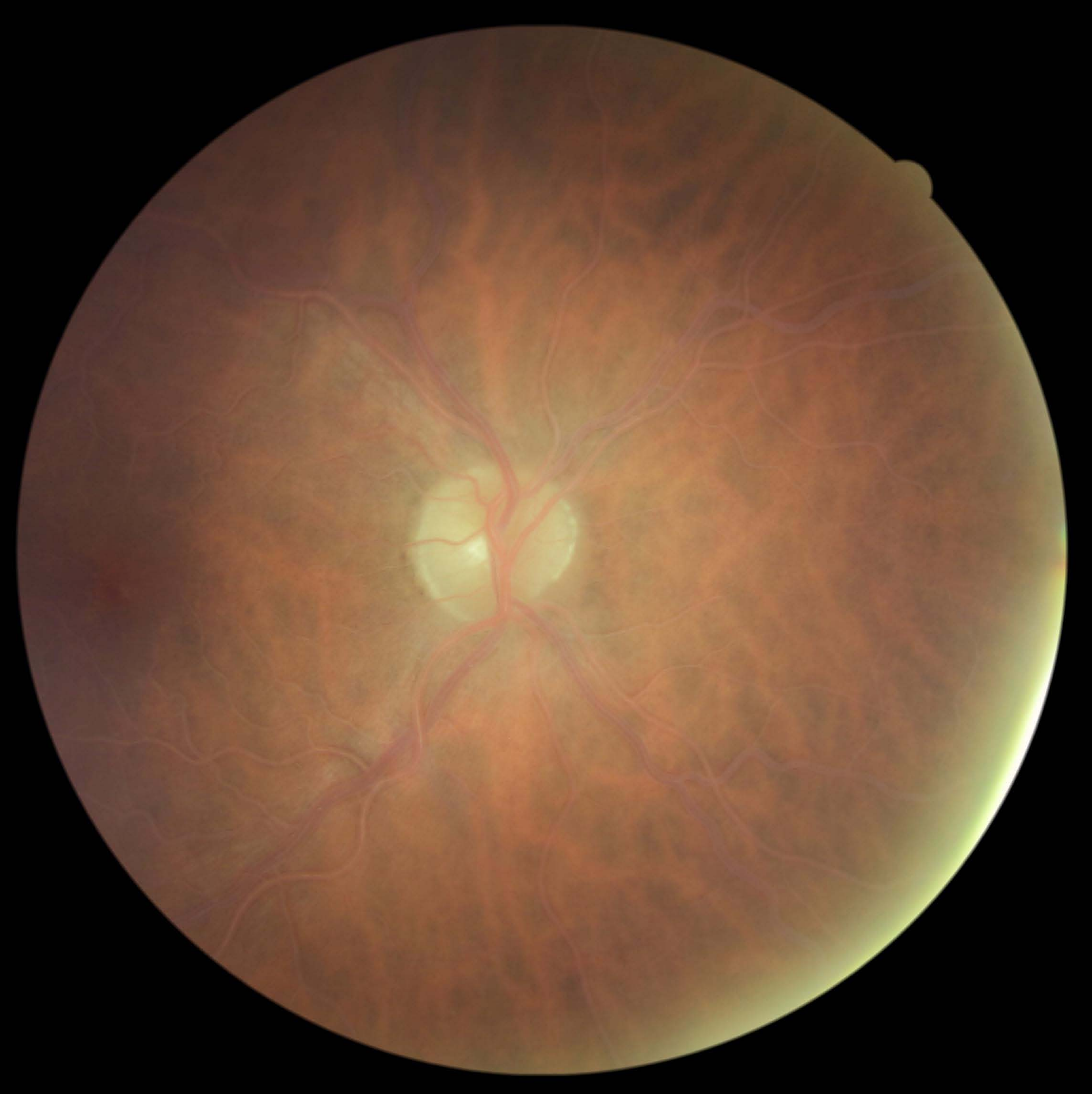




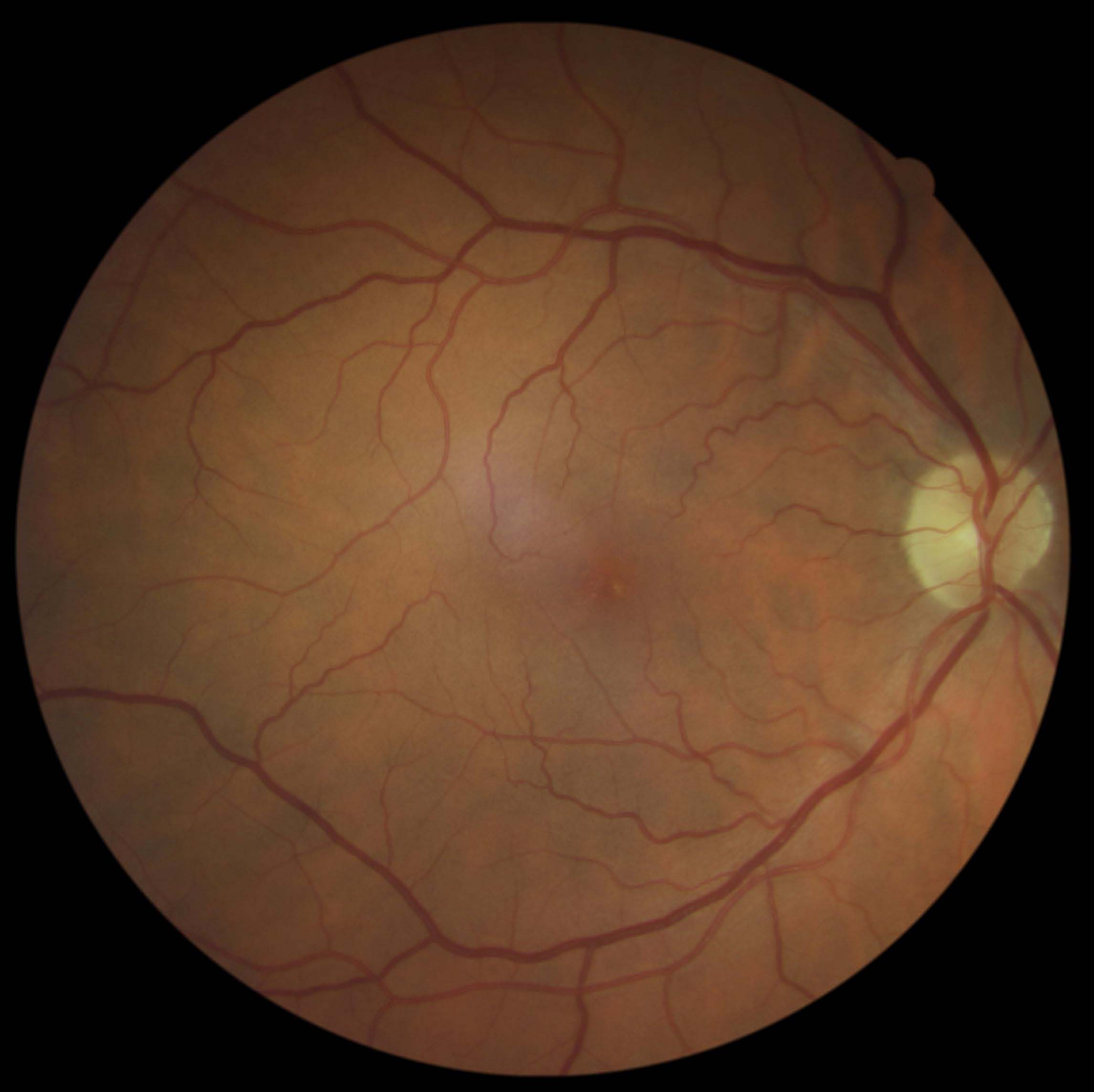




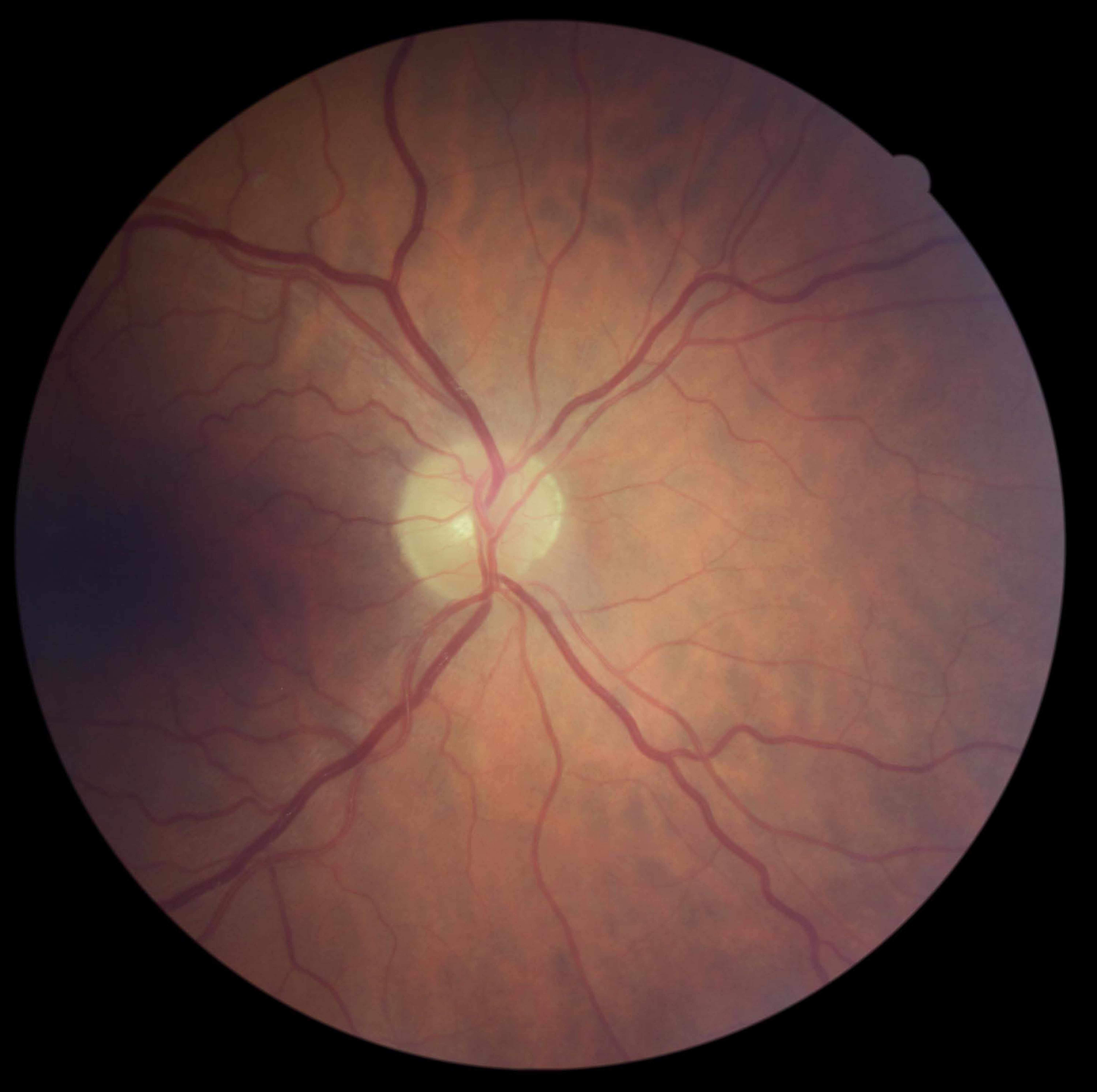

